\title{
Plano Educacional Individualizado para alunos com altas habilidades: Uma questão de avaliar Estratégias na Escola Regular
}

\author{
Débora dos Santos Silnal; Irineide Beserra Braga²; Petrucya Frazão Lira
}

Resumo: $O$ artigo pretende trazer à tona o debate acerca da importância de identificar os alunos com altas habilidades e aplicar/avaliar estratégias, em particular, o plano educacional individualizado para estes alunos dentro da escola regular, no intuito de possibilitar o crescimento adequado desta clientela no que diz respeito aos aspectos cognitivos, físicos, afetivos e emocionais. Para tanto, utilizou-se a metodologia de pesquisa bibliográfica, onde recorreu-se aos teóricos que especificam o que são as altas habilidades, quais suas necessidades no ambiente escolar e como atender a estas necessidades. Neste sentido, pôde-se perceber a dificuldade de se implantar uma cultura de identificação de tais alunos em virtude de mitos criados em torno das pessoas com altas habilidades e devido a problemas de adaptação e de assincronia que muitos destes estudantes enfrentam no contexto educacional. Conclui-se que atinar para as necessidades educacionais de alunos com altas habilidades é responsabilidade da escola regular que se propõe inclusiva e favorecedora do pleno desenvolvimento de seu alunado.

Palavras-chave: Inclusão. Altas habilidades. Plano educacional individualizado.

\section{Individualized Educational Plan for High Ability Students: A Matter of Evaluating Strategies in Regular School}

\begin{abstract}
This article aims to bring to the debate about the importance of identifying students with high abilities and implement / evaluate strategies, in particular, the individualized educational plan for these students within the regular school, in order to promote proper growth of this clientele with regard to the cognitive, physical, affective and emotional. For this, we used the bibliographic research methodology, where we used the theoretical specifying what are the high skills, which needs in the school environment and how to meet these needs. In this sense, we could realize the difficulty of deploying an identification culture such students because of myths created around people with high skills and because of problems of adaptation and asynchrony that many of these students face in the educational context. It follows that to fathom the educational needs of high ability students is regular school responsibility that proposes inclusive and favoring the full development of its students.
\end{abstract}

Keywords: Inclusion. High abilities. Individualized educational plan.

\section{Introdução}

Tornou-se lugar comum falar de pessoas com necessidades especiais seja no que se refere às relações familiares, escolares, sociais ou culturais. Exemplo disso é o fato de que a inserção e ampliação da acessibilidade nos variados ambientes em que estas pessoas precisam estar são assuntos por demais instaurados nos discursos daqueles que trabalham direta ou indiretamente com tais necessidades.

\footnotetext{
${ }^{1}$ Graduada em Psicologia pela Faculdade Leão Sampaio - FALS. Especialista em Educação Inclusiva com Ênfase em Atendimento Educacional Especializado e pós-graduanda (lato sensu) em Prática Docente do Ensino Superior pelas Faculdades Integradas de Patos - FIP. É membro titular do Comitê de Ética em Pesquisa da Faculdade de Juazeiro do Norte. E-mail para contato: deborassilva25@gmail.com ou debora.psicanalise@hotmail.com.

${ }^{2}$ Graduada em Psicologia pela Faculdade Leão Sampaio - FALS. Mestre em Ciências da Educação, Especialista em Saúde Mental pela Faculdade Leão Sampaio - FALS. Email: irineidebraga@msn.com.

${ }^{3}$ Enfermeira. Especialista em Nefrologia e Biologia. Mestranda em Ciência da Educação. E-mail: petrucyafrazao@ hotmail.com.
} 
Quando se fala em inclusão de pessoas com necessidades especiais na sociedade de um modo geral e na escola em particular, há uma tendência a criar uma imagem de pessoas com deficiências (mental ou física) e não levar em consideração, sobretudo em termos de realidade brasileira, as pessoas com altas habilidades: que também fazem parte do rol das necessidades especiais.

Dentro da escola, esta clientela raramente é identificada e, muitas vezes, pode ser considerada rebelde, inquieta, impaciente, desatenciosa e até se desempenhar abaixo de suas capacidades justamente pela dificuldade em adaptar-se às demandas da escola.

Neste sentido, tentar-se-á responder às seguintes perguntas: o que é uma pessoa com altas habilidades? Como identificá-la dentro da escola? Quais estratégias podem ser lançadas no intuito de oferecer tratamento educacional especializado a esta clientela? Como o plano educacional individualizado pode auxiliar estes alunos?

A questão é que na comunidade escolar os professores tendem a acreditar que os alunos com altas habilidades terão um futuro brilhante independente do auxílio do ambiente em que estiverem inseridos, sendo que, na verdade, se não tiverem suas necessidades educacionais atendidas podem, isto sim, experimentar profundos desajustes cognitivos, afetivos e emocionais.

Portanto, este trabalho tem por objetivo despertar a sensibilidade dos leitores para o percebimento de que os alunos com altas habilidades precisam de um atendimento especializado dentro da escola a fim de que suas capacidades possam ser plenamente desenvolvidas e para que seja reduzida grande parte do sofrimento que eles padecem na tentativa de se adequarem ou fugirem de um sistema educacional inapropriado para lidar com suas demandas.

\section{Método}

Para realizar a pesquisa utilizou-se o recurso do estudo bibliográfico que "[...] tem como alvo apoiar a redação de um projeto, um artigo ou um relatório, mas [que] para ser bem sucedido é importante ter bem claro seu objetivo" (TRAINA e TRAINA JR, 2009, p. 31). Objetivo que foi, neste trabalho, o de analisar as possibilidades de um plano educacional individualizado promover um melhor desenvolvimento acadêmico e social para pessoas com altas habilidades.

Este intento foi alcançado seguindo os passos a seguir traçados: levantamento dos teóricos que definem as características das pessoas com altas habilidades; inserção do debate acerca dos mitos e realidades envolvendo as Pessoas com Altas Habilidades (PAHs) no contexto escolar; compreensão das estratégias de atendimento educacional especializado a alunos com altas habilidades; estudo das estratégias de identificação e valorização das pessoas com altas habilidades na escola regular.

\section{Resultados e Discussões}

58 Id en lime Revista de Psicologia. Ano 9, No. 26, Supl. Esp. Abril/2015 - ISSN 1981-1179. Edição eletrônica em http://idonline.emnuvens.com.br/id 


\section{Mudança de Paradigma para uma escola inclusiva}

O debate em torno da igualdade de direitos tem acontecido em diversos segmentos sociais, a nível internacional e nacional. Nesse sentido, inúmeros protestos foram iniciados, congressos realizados, leis criadas e sancionadas no intuito de possibilitar a mudança de paradigmas frente aos pré-conceitos há muito incrustados no tecido social no que tange à diversidade de comportamentos. Assim é que conquistas e transformações foram acontecendo na lógica segregacionista da contemporaneidade capitalista.

Logo, a exemplo das discussões em âmbito mundial sobre igualdade de gêneros e relações homoafetivas, no Brasil têm ocorrido vários movimentos buscando alterações nas políticas pedagógicas, especificamente na mudança das concepções referentes às escolas especiais, integrais e inclusivas.

Portanto, de acordo com estas discussões o programa Educação Inclusiva: direito à diversidade, do Ministério da Educação, programa este iniciado em 2003, tem buscado auxiliar e proporcionar capacitação e formação específica para gestores e professores a fim de possibilitar educação para todos, educação esta que, segundo reza a Lei de Diretrizes e Bases da Educação Nacional, é dever da família e do Estado, movida pelos ideais de liberdade e solidariedade e objetivando o desenvolvimento, preparo para a cidadania e aperfeiçoamento para o trabalho (LDB, 1996).

Nesse sentido,

O programa afirma o direito de todos à educação, o acesso dos alunos com necessidades educacionais especiais à rede regular de ensino e introduz o debate sobre a diversidade na formação de gestores e educadores, de forma que as práticas do cotidiano escolar não reforcem as desigualdades pela limitação das perspectivas e expectativas de aprendizagem e participação; que passem a compreender as diferenças como parte da identidade de cada sujeito e não como um problema aos sistemas de ensino e às propostas educacionais. (DUTRA; GRIBOSKI, 2006, pp. 212-13)

Logo, este programa visa promover um olhar para a diversidade, entendendo-a não mais como um problema a ser sanado, mas, isto sim, como uma maneira diferente de ser no mundo e com os outros. Não cabe mais à escola conceber e enquadrar seus alunos em modelos herméticos de ser. É preciso que a escola valorize os potenciais e as múltiplas inteligências que seu corpo discente possui. Urge que a escola compreenda as necessidades de seu alunado: diferenciando para valorizar e igualando para respeitar.

As pessoas com necessidades especiais, parcela da sociedade que historicamente sofreu abusos físicos e mentais e foi expatriada do convívio social, tem atualmente o direito, garantido por lei, de exercer sua cidadania e de ter seu espaço dentro das escolas de ensino regular. Entretanto, percebe-se

59 Id en line Revista de Psicologia. Ano 9, No. 26, Supl. Esp. Abri//2015 - ISSN 1981-1179 Edição eletrônica em http://idonline.emnuvens.com.br/id 
uma postura estereotipada da sociedade em geral e de muitos especialistas no sentido de perpetuar ações para esta clientela dentro de escolas especiais (escolas para Superdotados, Associações de Pais e Amigos dos Excepcionais - APAES, etc.).

Não obstante, as escolas especiais não podem substituir a escola regular, sob pena de limitar o pleno desenvolvimento do aluno, já que, tirando-o do convívio com a alteridade, mantendo-o apenas nas escolas especiais ou em classe especial na escola regular, a educação termina por restringi-lo a uma mera integração nas atividades cognitivas, culturais e artísticas, porém, não possibilitando o amplo desabrochar de suas potencialidades enquanto cidadão.

É assim que a escola regular precisa garantir não só de direito, mas de fato a inserção e permanência em seus muros de todos,

[...] que têm sido reiteradamente excluídos dos sistemas de ensino - negros, meninas, homossexuais, índios, populações em situação de rua, adolescentes autores de ato infracional, crianças e jovens com dificuldades no processo de escolarização vinculadas ou não a causas orgânicas, superdotados/altas habilidades. Defendemos a equiparação de oportunidades, uma compensação da sociedade por não haver pensado na diversidade, para convertermos a Educação em prioridade! (VERONA, 2009, p. 11, grifo nosso).

É preciso que se construa um projeto político pedagógico que contemple a todos, independente de suas idiossincrasias e sempre orientado numa pedagogia centrada no aluno. Portanto, é imprescindível o papel do professor nesta tarefa de construção de uma escola voltada para a diversidade, para as várias formas de inteligência e afetividade.

Com efeito, o docente necessita, segundo Baptista (2006), para transformar-se em um professor inclusivo, apostar em dois planos: o do autoconhecimento e o da busca por referenciais de atuação. Autoconhecimento, na medida em que precisa lidar com muitas formas de subjetividade e de realidades, sendo que, para isso, necessita perceber o quanto estas vivências o afetam para que possa provocar em si mesmo movimentos de aceitação e/ou modificação do meio. Busca por referenciais, a partir do momento em que é fundamental recorrer a teóricos e propostas positivas que deram certo na história da educação para que se possa implantar um ensino inclusivo.

Sabe-se que o professor sozinho não conseguirá mudar a realidade social, precisa do apoio da escola e de seus diversos profissionais (coordenadores, diretores, equipe pedagógica, psicólogos, assistentes sociais). A escola, pois, deve estar pautada pelo ideário dos direitos humanos e permitir que aconteça em seu interior a criação de processos de ensino-aprendizagem, onde o foco de trabalho precisa ser o pleno desenvolvimento do aluno e não a sua limitação, dificuldade ou deficiência enquanto rótulo e esquema de manutenção de estereótipos. É assim que,

A educação inclusiva orientada pelos princípios dos direitos humanos e pela proposta pedagógica de que todos podem aprender passa a contrapor o paradigma tradicional da organização do sistema educacional, que conduzia políticas especiais 
para pessoas com deficiência definidas no modelo de segregação, com ênfase na abordagem clínica. Seguindo a lógica de escolas especiais organizadas a partir da identificação da deficiência ou do encaminhamento desses alunos para classes especiais, essas políticas conduziram a espaços segregados, entendidos como seu lugar de destino, que acabam por discriminar e excluir alunos em razão de deficiências, desvantagens, dificuldades e atitudes. (DUTRA e GRIBOSKI, 2006, p. 211)

Portanto, é interessante que aconteça uma mudança na concepção de pedagogia voltada para as pessoas com necessidades especiais com supervalorização das deficiências para uma pedagogia voltada para o compromisso com o ser humano e para o entendimento da possibilidade de aprendizagem independente de características físicas, sociais ou econômicas. A escola, com seus recursos estruturais e profissionais, precisa promover constante debate junto à comunidade para que novos modelos de educação comecem a ser trabalhados, para que as demandas populares passem a ser consideradas e uma sociedade diferente: pautada na identificação e valorização da diversidade, seja realmente construída. Ou seja, as escolas

[...] Devem reconhecer as diferentes necessidades de seus alunos e responder a elas, adaptar-se aos diferentes estilos e ritmos de aprendizagem das crianças e garantir um ensino de qualidade através de estudos apropriados, uma boa organização escolar, uma utilização adequada dos recursos e em relação com suas comunidades. (DOCUMENTO UNESCO apud ANDRÉS, 2010, p. 8)

\section{Pessoas com Altas Habilidades (PAHs): o problema da identificação e da valorização de suas necessidades especiais dentro da escola regular}

Quando o assunto é educação especial ou pessoas com necessidades especiais, na maioria das vezes vem à mente a questão das várias deficiências (mental ou física), entretanto, vale acrescentar que as pessoas com altas habilidades, que constituem cerca de 3 a $5 \%$ da população, também fazem parte do quadro de pessoas que precisam de cuidados especiais seja no lar ou na escola (RECH e FREITAS, 2005).

Para falar acerca das pessoas com altas habilidades no ambiente escolar ou educacional é necessário, inicialmente, que conceituemos o que vem a ser uma pessoa com tais habilidades.

Segundo Renzulli apud Andrés (2010) para se identificar uma pessoa com altas habilidades é preciso observar três características/traços comportamentais (modelo dos três anéis), a saber: habilidade acima da média em determinada área; forte envolvimento com a tarefa; e, criatividade. Valendo considerar que, para Renzulli, estes traços podem ser desenvolvidos em certas pessoas que demonstram capacidade acima da média; em algumas ocasiões visto que tais comportamentos não são contínuos - dependendo também do grau de envolvimento com a atividade; e, sob certas circunstâncias (ANDRÉS, 2010). Daí a necessidade de identificar a pessoa com altas habilidades para 
que sejam trabalhadas adequadamente suas necessidades educacionais, valorizando e ampliando suas possibilidades.

Neste sentido, o Projeto Escola Viva (2002) do Ministério da Educação, traçou indicadores com base na transcrição dos estudos de Whitmore, constantes em seu texto Características das crianças intelectualmente dotadas. Das características comportamentais gerais, de aprendizagem, de pensamento criativo, de pensamento crítico, de motivação, e de aspecto afetivo-emotivo, citadas pelo autor destacam-se as seguintes:

\section{- Características comportamentais gerais:}

Precocidade no domínio da linguagem falada e/ou escrita. Facilidade em aprender as capacidades básicas. Grande competência de análise. Menor conformismo. Ampla habilidade de trabalho individual. Ótima capacidade de concentração e atenção. Comportamento enérgico, intenso. Geralmente se relacionam bem com pessoas mais velhas. São altamente inquisitivos. Comportamento organizado e direcionado a resolução de metas e busca por concretização de objetivos. Possuem motivação própria e gostam de conquistar ou aprender coisas novas.

\section{- Características de aprendizagem:}

Grande capacidade de atenção a detalhes, observação e insight. Demonstram prazer nas atividades intelectuais com excelentes capacidades de abstração, conceituação e síntese. Mostram-se questionadores e curiosos frente a informações e acontecimentos. Podem armazenar muita informação sobre os mais diversos assuntos. Capacidade de manipular problemas complexos dividindo-os em partes no intuito de solucioná-los.

- Características de pensamento criativo:

São pensadores fluentes, flexíveis, originais, elaborativos. Obtém prazer em se aprofundar em temas complexos, em jogos intelectuais. Sensíveis emocionalmente. Possuem sensibilidade estética. Curiosos sobre o desconhecido. São desinibidos no que se refere a questões cognitivas.

\section{- Características de pensamento crítico:}

Possuem uma tendência a divergir verbalmente das ideias que consideram erradas nos outros: não importando quem seja. Tendência ao perfeccionismo, sendo, portanto, autocríticos e críticos dos outros. Além de uma forte disposição para dominar os demais.

- Características de motivação:

Dificuldade em tolerar autoridade. Inconformismo e obstinação. Dificuldade em deixar uma atividade que lhe seja interessante. Tendência a discordar. Falta de interesse em tarefas rotineiras. Recusa por atividades que não apresentem um desafio a transpor.

\section{- Características afetivo-emotivas:}

Hipersensibilidade emocional a críticas dos outros ou a situações que não surtiram o resultado esperado. Tendência a recusar atividades que avaliem não poderem realizar adequadamente. 
Ampliando as ideias descritas sobre a identificação de uma PAH, Cupertino (2008) menciona que geralmente se observa uma assincronia no desenvolvimento global do sujeito; ou seja, algumas funções terminam por se desenvolverem mais precocemente e com maior grau do que outras que ficam no nível da normalidade ou abaixo dele. Assim, no que se refere à assincronia “[...] exceto os raríssimos casos de pessoas com múltiplas capacidades, há uma habilidade predominante que se destaca das demais [...]: a pessoa faz aquelas coisas mais, melhor que os outros, e melhor que as outras coisas que ela mesma faz" (CUPERTINO, 2008, p. 20).

Assim, é importante compreender que estes comportamentos manifestos podem ser monitorados ou avaliados através da observação direta, conversa, questionários, classificação de características, entrevistas (com os pares do aluno avaliado), até por meio de "testes, desde que usados mais como metáforas da vida real do que em busca de resultados numéricos absolutos" (CUPERTINO, 2008, p. 25). Ou seja,

Há muitas estratégias para se identificar o aluno com altas habilidades/superdotação. [Porém] A atitude mais recomendável entre os especialistas é a inclusão de múltiplas formas de avaliação, buscando dados sobre os talentos e capacidades de alunos tanto em testes formais quanto em procedimentos informais e de observação (VIRGOLIM, 2007, p. 58).

Entretanto, na realidade, existe uma grande dificuldade em se identificar e implantar políticas dentro das escolas para as crianças e adolescentes com altas habilidades. Estas dificuldades podem ser citadas a partir das análises a priori feitas por parte da sociedade acerca de tais pessoas.

A este respeito, pode-se trazer à baila um estudo feito por Rech e Freitas (2005) acerca dos mitos criados por parte da sociedade em geral e da escola em particular envolvendo os alunos com altas habilidades. Nesta pesquisa, elas avaliaram a realidade de uma escola na cidade de Santa Maria, no Rio Grande do Sul, e puderam fazer um levantamento de nove mitos que perpassam o imaginário popular sobre a clientela em questão. Abaixo foram transcritos os mitos:

- As altas habilidades são características genéticas;

- Dependem exclusivamente do estímulo ambiental;

- Os pais destes alunos são organizadores dos estímulos;

- As pessoas com altas habilidades procedem de classe socioeconômica privilegiada;

- Não se devem identificar as pessoas com altas habilidades;

- A PAH se destaca em todas as áreas do currículo escolar. É aluno nota dez em tudo;

- Crianças com altas habilidades serão adultos de destaque;

- Tudo é fácil para elas;

- Não precisam de atendimento educacional especial. 
Estes mitos acabam caindo por terra a partir do momento em que se promove uma reflexão em torno deles e se observa a pouca fundamentação lógica e real para sua sustentação.

A verdade é que a situação das PAHs não é das mais fáceis como se poderia pensar ao analisar apenas as grandes capacidades cognitivas que elas apresentam. O fato é que os alunos com altas habilidades nem sempre são identificados e valorizados na escola regular pelos educadores. Às vezes suas características comportamentais são percebidas de forma distorcida pelos professores que lêem iniciativa e auto-suficiência como uma tendência a dominar a discussão, concentração e foco como obstinação e resistência à interrupção, independência e inconformismo como rebeldia e oposição, hipersensibilidade como hiperatividade, déficit de atenção (RECH; FREITAS, 2005).

Não raro o professor acaba por considerar o aluno com altas habilidades enquanto um rival, um competidor, quando, na verdade, tal estudante é apenas alguém que gosta de se sentir estimulado e desafiado intelectualmente. Sendo que "[...] sem estímulo, essa pessoa pode desprezar seu potencial elevado e apresentar frustração e inadequação ao meio." (RECH; FREITAS, 2005, p. 13).

Ademais, as dificuldades encontradas pela pessoa com altas habilidades no que se refere à compreensão por parte dos outros sobre suas características e interesses pode terminar causando “[...] problemas psicológicos nestes sujeitos que podem estagnar-se e acomodar-se ao sistema. Esta acomodação pode restringir conquistas futuras, influenciando na sua vida pessoal e social" (NEGRINI, 2012, p. 03). É neste sentido que muitas PAHs acabam disfarçando suas reais capacidades no intuito de se sentirem aceitas pelos pares (NEGRINI, 2012). Além disso, características como: perfeccionismo, autocrítica, sensibilidade em demasia atrelados a questões emocionais são apontados enquanto origem de problemas para aqueles com altas habilidades intelectivas (ALENCAR, 2007).

Com efeito,

[...] Essas crianças [as PAHs, de modo geral] são caracterizadas afetivamente por uma grande sensibilidade, proveniente da acumulação de uma quantidade maior de informações e emoções [...] do que [...] pode [m] absorver e processar [...] Um programa adequado deve dar oportunidades para que [...] tenha [m] consciência dos seus aspectos emocionais, ajudando-a [s] a aplicar suas habilidades verbais e de compreensão avançadas às suas experiências emocionais. A consciência social, que frequentemente aparece cedo no desenvolvimento destas crianças, torna-se uma oportunidade para se desenvolver nelas uma adequada estrutura de valores e de transformar valores em ações sociais. (VIRGOLIM, 2007, p. 44)

\section{Quais as estratégias existentes de auxílio aos alunos com altas habilidades dentro da escola?}

No que diz respeito "[...] às políticas públicas educacionais, estas subsidiam o atendimento em sala de aula regular e em sala de recursos para os estudantes com altas habilidades/superdotação, considerando suas peculiaridades individuais" (NEGRINI, 2012, p. 06). Ademais o atendimento "[...] pode ser realizado em conjunto com outras instituições de ensino, seja de ensino superior ou núcleos 
de atividades, para suplementação da aprendizagem destes estudantes, enriquecendo o ensino regular." (NEGRINI, 2012, p. 06).

Segundo Cupertino (2008) existem três tipos de estratégias de atendimento para estudantes portadores de altas habilidades, a saber: agrupamentos, aceleração e enriquecimento. Portanto, a descrição abaixo sobre as estratégias citadas baseiam-se no estudo de Cupertino. Valendo sinalizar que estas táticas precisam sempre estar pautadas em métodos flexíveis.

- Os agrupamentos: dizem respeito à união de pessoas com habilidades e interesses semelhantes. Dentro da escola é preciso ter em mente que o agrupamento deve ser utilizado apenas para favorecer um melhor aproveitamento das capacidades dos alunos com altas habilidades ao fomentar a motivação dos mesmos, cuidando para estes alunos não serem vistos como privilegiados: diferentes sim, superiores não.

- A aceleração: refere-se à possibilidade de pular etapas do ensino regular, podendo ocorrer de diversos modos: início precoce na instituição escolar, isenção de cursos ou disciplinas, constituição de quadros de estudos no ritmo adequado para o aluno. Para que a aceleração ocorra é preciso levar em consideração não só os aspectos cognitivos, mas também os aspectos afetivos, físicos e emocionais do aluno.

- O enriquecimento: é a estratégia que oferece maiores disciplinas e/ou estímulos além daqueles ofertados regularmente. Tendo como vantagem possibilitar a permanência do aluno com os colegas de mesma idade e a ampliação de suas capacidades. São exemplos de enriquecimento a adição de assuntos mais aprofundados, solicitação de projetos novos e as adaptações curriculares (o plano educacional individualizado entra nesta categoria).

\section{Plano educacional individualizado: sua importância na aplicação de estratégias e valorização dos alunos com altas habilidades}

O plano educacional individualizado entra como possibilidade, depois de realizada a identificação do aluno com altas habilidades por parte do professor, junto com a equipe de apoio pedagógico. O plano pretende nortear as atividades dos educadores junto a esta clientela e frente às características peculiares de cada estudante.

Segundo o projeto Escola Viva (2002), do ministério da educação, o plano individualizado/relatório de ensino deve ser encaminhado para os professores na intenção de possibilitar a efetivação das atividades previstas, devendo, portanto, conter:

1.Uma caracterização pormenorizada das características do aluno, em seu processo de aprendizagem; 2.A descrição e caracterização do conjunto de suas necessidades 
educacionais especiais; 3.A explicitação das adaptações de grande e de pequeno porte (de acesso ao currículo, de objetivos educacionais, de conteúdo, de método e avaliativas), que se mostram necessárias para atender às necessidades educacionais especiais identificadas; 4.A explicitação clara e objetiva das metas (PROJETO ESCOLA VIVA, 2002, p. 24).

Ou seja, o plano de ensino visa possibilitar um olhar diferenciado aos alunos que apresentem altas habilidades. Valendo salientar que o conceito de altas habilidades envolve a observação e identificação (por parte dos professores, orientadores e coordenadores) de estudantes com talentos precoces e extraordinários em uma ou várias das áreas e atividades trabalhadas pela escola. Estas habilidades, como já citado, salvo casos raros de aptidões múltiplas, dizem respeito a um grande desenvolvimento em determinado campo e um desenvolvimento normal ou abaixo da média em outro. Um exemplo disso é encontrado em alunos com excelentes desempenhos em matérias da área das ciências exatas (matemática, física e química) e déficits consideráveis em matérias das ciências humanas (português, e história) ou ainda alunos ótimos para interpretar situações que envolvam a abstração, porém, péssimos no manejo das relações emocionais e afetivas. Assim,

Diferentemente do que se imagina, a criança superdotada não é necessariamente um "gênio". Por causa dessa confusão, a palavra "superdotado" está sendo substituída pela expressão "com altas habilidades". O aluno com essa característica está acima da média na escola, nos esportes, nas artes, na criatividade ou na liderança. No caso da habilidade intelectual, o estudante pode ter um desempenho excepcional em determinada disciplina escolar, mas não ser bom nas demais. Calcula-se hoje que de $15 \%$ a $20 \%$ da população tenha altas habilidades [sendo que esta grande quantidade populacional termina por não ser identificada nos estudos oficiais]. (DIMENSTEIN apud ANDRÉS, 2010, p. 21, grifo nosso).

Identificar a existência de alunos com estas assincronias é importante na medida em que tal intervenção tem por finalidade promover qualidade de vida e favorecer o desabrochar do potencial científico e tecnológico que alunos com altas habilidades podem oferecer ao bom funcionamento da sociedade. Neste sentido, também é importante na elaboração do plano atentar para os dados familiares, para as habilidades e dificuldades no que se refere à interação com colegas e crianças de mesma idade, recursos utilizados para o aprendizado, além das medidas ou metas que deverão ser aplicadas e os critérios para avaliação das implantações e do desempenho do educando.

Portanto, o atendimento especializado via plano educacional para alunos com altas habilidades, propõe estabelecer com estes: atividades que despertem seus interesses para os conteúdos ofertados pelos professores na aula regular, na medida em que fomentem respeito por suas ideias e curiosidade. Lembrando que, estes alunos, por mais que apresentem ótima memória, atenção concentrada, liderança, autonomia, iniciativa, imaginação e perseverança nas atividades que lhes estimulem; entretanto, estas qualidades não garantirão um futuro brilhante para os mesmos, já que estes alunos, caso não tenham suas necessidades educacionais atendidas, podem mostrar, segundo Ourofino e Guimarães, citados por Cupertino (2008), alguns problemas no que se refere à socialização 
com colegas de sala e/ou de mesma idade, busca excessiva pela perfeição, intolerância a críticas, comportamentos desajustados, desinteresse frente aos trabalhos do currículo regular da escola, e até evasão escolar pela ausência de estímulos em suas habilidades desafiadoras.

Sendo que, muitas vezes, os próprios professores desenvolvem uma atitude defensiva para com tais alunos por diversos motivos, entre eles: dificuldade em compreender suas necessidades ou por perceberem neles comportamentos de oposição, já que muitas vezes colocam em xeque os conteúdos ministrados pelo docente - desafiando, pois, sua autoridade e conhecimento.

A elaboração de um plano de ensino individualizado se justifica na medida em que pretende incentivar os alunos com altas habilidades, implantando métodos para trabalhar, junto com a comunidade escolar, formas de manter o interesse deles frente ao currículo regular, mas promovendo modos de estimulação e fornecendo à curiosidade exacerbada e ao intelecto super desenvolvido maneiras de socialização com os demais. Lembrando que estas formas mantenedoras do interesse do aluno nas disciplinas ofertadas pela escola devem ser flexíveis e sempre condizentes com suas necessidades. Possibilitando, ainda, a quebra de possíveis atitudes preconceituosas ou de bullying dentro da escola no que tange a estes estudantes. Já que,

[...] as altas habilidades caracterizam uma necessidade especial que, ao contrário das demais, não é perceptível imediatamente. A maioria das deficiências é mais fácil de identificar. Por seu caráter multidimensional, as altas habilidades não são altoevidentes, e, além disso, o assim chamado superdotado não pode ser identificado com base em categorias totalizantes [...] [o] que faz com que as pessoas se sintam inseguras em assumir posições que, de acordo com elas, significam rotular o aluno (CUPERTINO, 2008, p. 64).

\section{Considerações Finais}

A inclusão de alunos com altas habilidades na escola regular foi tema deste trabalho que procurou conhecer o universo destas pessoas: suas características, possibilidades e limitações. Neste sentido, com a elaboração deste artigo pôde-se entender o que é uma pessoa com altas habilidades, perceber a importância de identificá-la no ambiente escolar ou educacional a partir da observação (incluindo-se aí a aplicação de questionários, entrevistas, testes que sejam utilizados mais como apoio do que como determinantes do sujeito) de características gerais, de aprendizagem, de pensamento criativo, crítico e no que tange à motivação e aos aspectos afetivos e emocionais.

Além disso, foram trazidas ao debate as ideias, mitos ou representações que as pessoas em geral e os professores/comunidade escolar têm das pessoas com altas habilidades e ainda as dificuldades que muitos docentes experimentam em compreender e interpretar as características e necessidades destes alunos. 
Também foram discutidas as questões englobando o problema da identificação de tais alunos, visto que, muitas pessoas tendem a confundir altas habilidades com superioridade ou a pensar que, identificando tais pessoas no ambiente escolar, estarão privilegiando-as em detrimento das outras. Pensamento este não condizente com a realidade onde tais pessoas, caso não tenham suas necessidades educacionais atendidas, podem vir a sofrer graves danos em seu desenvolvimento na medida em que tais habilidades acima da média prescindem de forte envolvimento com a tarefa e criatividade, traços estes que não podem ser ampliados e aperfeiçoados em ambientes que tamponem e/ou não estimulem estas capacidades.

Portanto, as pessoas com altas habilidades dentro do ambiente escolar devem ser identificadas e valorizadas a partir de estratégias educacionais que possam abarcar o tamanho leque de interesses que possuem. Também devem ser trabalhados os aspectos afetivos e emocionais destes sujeitos que muitas vezes apresentam assincronias no desenvolvimento. Por isso é que, a nosso ver, deve-se primeiramente focar, quando da identificação de uma alta habilidade em determinado aluno, o desenvolvimento de um plano educacional individualizado que possa ser aplicado e avaliado continuamente no intuito de perceber avanços ou de corrigir defeitos nas metodologias aplicadas, considerando-se sempre os aspectos singulares de cada estudante.

Com efeito, a identificação dos alunos com altas habilidades no contexto escolar ou educacional é ainda um grande problema a ser resolvido. Entretanto, o fato de não se identificar e, assim, possibilitar métodos educacionais adequados a estes alunos não impede a existência deles dentro da escolar regular. Muitas vezes tais estudantes mascaram seus potenciais por medo de serem ridicularizados ou segregados, e assumem uma atitude conformista para com o sistema em que estão inseridos. Outros, mais questionadores e hipersensíveis à falta de compreensão por parte dos educadores, acabam por assumir uma postura de oposição e estranhamento para com a lógica escolar, podendo vir a ser expulsos ou a desistir do ensino formal. Outros, podem até chegar a recorrer a métodos mais extremados como o suicídio ou homicídio como forma de aplacar a dor ou experimentar vingança. Outros podem recorrer a métodos ilícitos de conseguir riqueza (exemplo: os hackers que invadem contas de pessoas físicas ou jurídicas no intuito de furtar grandes somas de dinheiro).

Enquanto muitos professores não conseguem (ou não querem) identificar as altas habilidades de determinado aluno, os colegas, por sua vez, muitas vezes percebem as capacidades elevadas do companheiro de sala e se utilizam delas em benefício próprio. Já que, a pessoa com altas habilidades pode assumir uma atitude de medo e/ou receio de perder a amizade dos demais em virtude mesmo de funcionar diferentemente, vindo a sofrer, assim, pressão por parte dos pares para resolver suas atividades e trabalhos escolares.

Portanto, do mesmo modo que alguém pode ser vitima de bullying na escola por apresentar alguma diferença ou imperfeição física (a depender do que se considere beleza em determinado período e/ou lugar) também o aluno com altas habilidades pode ser vitimizado, sufocado e pressionado 
a ajudar os colegas de sala. Sendo que, o plano educacional individualizado poderá evitar esse tipo de situação na medida em que favoreça o percebimento das potencialidades e limitações (intelectuais, físicas, emocionais, etc.) do estudante com altas habilidades, fomentando o enriquecimento das aulas a partir do aprofundamento dos temas, inserção de projetos de estudo elaborados pelo estudante e até incentivando um trabalho de monitoria ou de ajudante do professor, porém, não de forma coercitiva, mas prazerosa: onde possam ser gerados produtos quantitativos e qualitativamente saudáveis para todos os envolvidos.

\section{Referências}

ANDRÉS, A. Educação de alunos superdotados/altas habilidades: legislação e normas nacionais, legislação internacional, 2010. Biblioteca digital da Câmara dos Deputados.

ALENCAR, E. M. L. S. Características sócio-emocionais do superdotado: questões atuais. In. Psicologia em estudo. Maringá, v. 12, n. 2, 2007.

BAPTISTA, C. R. Inclusão em diálogo: algumas questões que insistem... In. Ensaios pedagógicos: III seminário nacional de formação de gestores e educadores - educação inclusiva: direito à diversidade. Brasília: Ministério da Educação. Secretaria de Educação Especial, 2006.

CUPERTINO, C. M. B. (Org.). Um olhar para as altas habilidades: construindo caminhos. Secretaria da Educação, CENP/CAPE. São Paulo: FDE, 2008.

DUTRA, C. P.; GRIBOSKI, C. M. Educação Inclusiva: um projeto coletivo de transformação do sistema educacional. In. Ensaios pedagógicos: III seminário nacional de formação de gestores e educadores - educação inclusiva: direito à diversidade. Brasília: Ministério da Educação. Secretaria de Educação Especial, 2006.

LEI DE DIRETRIZES E BASES DA EDUCAÇÃO NACIONAL. Lei nº 9.394, de 20 de dezembro de 1996.

MANTOAN, M. T. E. Inclusão Escola - caminhos e descaminhos, desafios, perspectivas. In. Ensaios pedagógicos: III seminário nacional de formação de gestores e educadores - educação inclusiva: direito à diversidade. Brasília: Ministério da Educação. Secretaria de Educação Especial, 2006.

NEGRINI, T. As práticas educacionais frente ao desafio da inclusão dos estudantes com altas habilidades/superdotação. XVI ENDIPE, Encontro Nacional de Didática e Práticas de Ensino, UNICAMP, Campinas, 2012.

PROJETO ESCOLA VIVA - Garantindo o acesso e permanência de todos os alunos na escola Alunos com necessidades educacionais especiais. Identificando e atendendo as necessidades educacionais especiais dos alunos com altas habilidades/superdotação. Brasília: Ministério da Educação, Secretaria de Educação Especial, 2002.

RECH, A. J. D; FREITAS, S. N. Uma análise dos mitos que envolvem os alunos com altas habilidades: a realidade de uma escola de Santa Maria/RS. In. Rev. Bras. Ed. Esp., Marília, v.11, n.2, 2005. 
TRAINA, A. J. M; TRAINA JR., C. Como fazer pesquisa bibliográfica. In. SBC Horizontes, v.2, n. $2,2009$.

VERONA, H. Apresentação. In. Educação Inclusiva: experiências profissionais em psicologia. Conselho Federal de Psicologia. Brasília: Conselho Federal de Psicologia, 2009.

VIRGOLIM, A. M. R. Altas habilidades/superdotação: encorajando potenciais. Brasília: Ministério da Educação, Secretaria de Educação Especial, 2007.

\section{Como citar este artigo (Formato ABNT):}

SILVA, D.S.; BRAGA, I.B.; LIRA, P.F. Plano Educacional Individualizado para alunos com altas habilidades: uma questão de avaliar estratégias na Escola Regular. Id on Line Revista de Psicologia, Abril de 2015, vol.9, n.26, Supl. Esp. p. 57-70. ISSN 1981-1189.

Recebido: 10/01/2015

Aceito:12/02/2015 